Likewise in E.C.T. I have lived with 600 epileptics for five years, and if one worried about everything that could happen to them (but yet so rarely does), one would have them permanently in bed under light thiopentone and $d$-tubocurarine chloride.

I only want to ask this question of my psychiatric colleagues (except Dr. Sandison, who is on my side). If you had to have E.C.T., wouldn't you like to have the button pressed first, and an adequate routine laid on to prevent your injury and/or demise after you were "out," or would you, like me, probably die of fright, before you could be resuscitated, when you had (1) been buckled into your canvas jacket ; (2) had your straps secured; (3) had your leather headband put on; (4) received your injection/injections, or any other refinement calculated to prevent your receiving an injury which may never happen if the simplest method is used, and would be better than dying of (a) fright and (b) medication, anyway ?-I am, etc.,

$$
\text { Dartford, Kent. }
$$

J. Mackay CRAwford.

\section{Folic Acid}

SIR,-I have been interested in the leading article (May 3, p. 604) concerning folic acid as a therapeutic agent, and perhaps I may be excused for bringing to your notice a single case of subacute combined degeneration of the cord which has recently been under my care.

The patient, a male aged 55 years, when I saw him first had been suffering for three months with loss of power in the legs, unsteadiness, marked sensation of cold spreading up the legs when standing, tingling, and numbness. On examination the findings were those of a spastic ataxia, the blood that of a pernicious anaemia. He could not stand without support and

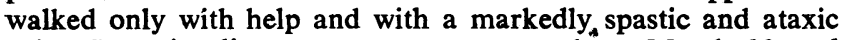
gait. Intensive liver treatment was started on March 20 and continued for three weeks, with marked improvement in the blood state but only slightly in the nerve condition.

I then administered folic acid $10 \mathrm{mg}$. daily and gave a maintenance dose of liver weekly. Within a few days a marked improvement took place and has continued since, reaching a climax to-day, when I saw him walking, using a bicycle as a partly moral and partly physical support, a mile distant from his home.-I am, etc.,

Birkenhead.

CECIL L. FORDE.

\section{Shortage of Nurses}

SIR,-Dr. R. Howell Roberts suggests (May 10, p. 655), that professional examination of "orderlies" for higher rank in the three Services should be brought into line with civilian standards. Surely, Sir, the boot is on the other foot! Sick berth ratings passed for higher rates in the Navy, their opposite numbers in the other Services, and the V.A.D.s who have had similar training and experience during the late war are recognized as nurses fit to be entrusted with the care of the sick in the Services.

If the General Nursing Council could forget its obsession with examination standards and its own importance it might make a real contribution to the serious national shortage of nurses by accepting these ex-Service men and women as qualified nurses and granting them State registration on their discharge from the Services, with recommendation for such registration by the relevant Service medical authorities.

No man or woman after several years of responsible nursing will consider beginning again to "train" for the State Registered Nurse examination under existing rules, but many are experienced nurses well worthy of inclusion in the Register forthwith. The General Nursing Council must get down from its high horse and face the facts.-I am, etc.,

SURGEON COMMANDER, R.N.

\section{Congenital Malaria}

SiR,-Dr. P. G. Preston's letter (March 29, p. 422) impels me once more, as on a similar occasion last year, to attack the complacency of reporters of alleged instances of the above alleged syndrome. As a much examined student from whom. examiners require much accuracy of statement and quotation, I deplore the almost universal failure of reporters in this field to present their alleged facts, which may be facts indeed, in anything remotely approaching a scientific or factual manner which can readily be understood and accepted.

To quote from the letter under "deplorement": "blood was taken .... on three consecutive days following its birth." Were these the first three days after birth, or the 8th, 9th, 10th, or the thousand-and-first, etc.? And again: "out of 700 patients examined $\mathbf{4 0}$ mothers were found to have malaria parasites in the placental blood, and two infants." This second phrase gives no factual information and is capable of various interpretations, among them a comical one, which is, however, relevant to my argument-i.e., that twin infants were found in the placental blood. The latter interpretation calls to attention one of the many factors which have to be considered and eliminated before a true bill can be presented for congenital malaria, that is, the possibility of post-partum infection by placental or maternal blood through abrasions, the severed cord, or even the dekicate mucous membranes of the infant.

As I contended on a previous occasion, few if any alleged discoverers of congenital malaria have advanced fool-proof scientific evidence of their discoveries-at least not enough to satisfy an advanced student.-I am, etc., India.

STUdeNT No. 2.

\section{Responsibility for Drugs Supplied}

SIR,-I would suggest an alternative to the "disturbing and crushing alarm" expressed in the medico-legal article (March 29, p. 428) at the prospect of practitioners' being liable to heavy damages for the possible damage done to their patients by new preparations recommended by drug-retailing firms. Instead, should we not perhaps take it as a timely warning of the bad state into which our clinical medicine to-day is drifting? Did each of us do six or more years of intensive study to be led continually "by the nose" by laboratory chemists and the large financial considerations that are behind the drug-retailing firms ? Why do we experiment on our patients on the advice of attractive pamphlets that litter our breakfast-tables each morning ?

I would suggest that it is chiefly due to two reasons which we might well try and rectify immediately: (1) The inability of the average overworked practitioner to attend refresher courses at least every two or three years. In consequence of this he is much too much a willing victim to the commercial drug concerns in a blind effort to keep up with the times. (2) If in our student years and in the medical literature thereafter disease was analysed and studied $a$ little less and a positive approach to the natural health of body and mind synthesized and considered a little more, then perhaps our impulse to be influenced by the often ignorant demands of our patients for useless bottles of medicine and possibly harmful injections would be changed to a bold, clear resolve to attempt to change and remedy some of the many bad habits of living and eating of our time.

The cycle of a healthy soil through natural composting leading to healthy, pest-free vegetation and thence to healthy, disease-free animals has already been overwhelmingly scientifically proved after the artificial manures, chemical sprays, and injections had all lamentably failed. Man is an intrinsic part of that cycle, and the sooner that we use fewer bottles of medicine, sprays, and injections and help our patients back into that natural cycle of real health that the more progressive agricultural experts have already discovered and utilized so the sooner, among the many enormous benefits to mankind, will be solved the little problem of safeguarding our pockets from harm we may do our patients, because such a state of affairs will happily no longer arise.-I am, etc.,

Madeira.

H. P. KILSBY.

\section{William Blake Psychologized}

SIR,-It was only to be expected that, with the contemporary break-up of social organization, there should to-day show itself a parallel tendency to mental dissociation, taking many forms and constituting the starting-point of numerous serious psychopathies. Although personally unacquainted with William Blake's prophetic books, I am interested to read that the strange dramatis personae, with their uneouth names, in these poems represent symbolically a "disintegration" of the soul or uncon- 